\title{
SARS Coronavirus Detection Methods
}

\section{Susanna K.P. Lau, ${ }^{*}$ Xiao-Yan Che, $\dagger$ Patrick C.Y. Woo, ${ }^{*}$ Beatrice H.L. Wong, ${ }^{*}$ Vincent C.C. Cheng, ${ }^{*}$ Gibson K.S. Woo, ${ }^{*}$ Ivan F.N. Hung, ‡ Rosana W.S. Poon, ${ }^{*}$ Kwok-Hung Chan, ${ }^{*}$ J.S. Malik Peiris, ${ }^{*}$ and Kwok-Yung Yuen*}

Using clinical samples from patients with severe acute respiratory syndrome, we showed that the sensitivities of a quantitative reverse transcription-polymerase chain reaction ( $80 \%$ for fecal samples and $25 \%$ for urine samples) were higher than those of the polyclonal (50\% and $5 \%$ ) and monoclonal (35\% and $8 \%$ ) antibody-based nucleocapsid antigen capture enzyme-linked immunosorbent assays.

$\mathrm{T}$ he epidemic of severe acute respiratory syndrome (SARS) in 2003, caused by SARS-associated coronavirus (SARS-CoV), has affected 30 countries, with 8,098 cases and 774 deaths (1-8). Early diagnosis of SARS-CoV infection, which involves viral detection, is important for preventing future epidemics. Since culturing of SARS$\mathrm{CoV}$ is difficult and insensitive, the reverse transcriptionpolymerase chain reaction (RT-PCR) and quantitative RTPCR (qRT-PCR) has been the working standard in diagnosis $(2,9)$. Nevertheless, these techniques are relatively expensive and rely on the availability of equipment and expertise. We recently reported the development of 2 sandwich enzyme-linked immunosorbent assays (ELISAs) for detection of SARS-CoV nucleocapsid protein in clinical specimens of SARS patients $(10,11)$. However, no studies have been conducted to compare the sensitivities of ELISA with those of RT-PCR. Although PCR assays are generally more sensitive, ELISAs are less expensive and easier to conduct $(12,13)$. To evaluate the potential usefulness of ELISA in diagnosing SARS-CoV infections, we compared the performance of ELISA and qRT-PCR and studied the correlation between their results.

\section{The Study}

Fecal specimens ( $\mathrm{n}=40$, from 40 patients $1-27$ days after symptom onset) and urine specimens $(n=133$, from 101 patients $2-57$ days after symptom onset) were collected from SARS patients hospitalized in Hong Kong from

\footnotetext{
*University of Hong Kong, Hong Kong Special Administrative Region, People's Republic of China; †First Military Medical University, Guangzhou, People's Republic of China; and ¥Queen Mary Hospital, Hong Kong Special Administrative Region, People's Republic of China
}

March to May 2003. SARS was confirmed by the presence of serum immunoglobulin (Ig) G against SARS-CoV by an immunofluorescence assay (4). Specimens were tested with polyclonal and monoclonal antibody-based capture ELISAs for SARS-CoV nucleocapsid protein and realtime qRT-PCR. Control urine $(n=100)$ and fecal $(n=100)$ specimens were obtained from hospitalized patients without SARS.

SARS-CoV nucleocapsid protein was detected by polyclonal antibody-based ELISA according to published protocols $(7,11)$. SARS-CoV nucleocapsid protein was detected by monoclonal antibody-based ELISA using a modified protocol for serum samples (10). Briefly, fecal and urine specimens were inactivated with $2 \%$ and $0.5 \%$ phenol, respectively, for 15 min before centrifugation and dilution in phosphate-buffered saline with $2 \%$ skim milk. One hundred microliters of 1:10 diluted fecal specimens or 1:2 diluted urine specimens was added to wells previously coated with antinucleocapsid monoclonal antibodies. Plates were incubated, washed, treated with antinucleocapsid rabbit monoclonal antibodies, and analyzed as described previously $(10,11)$. RNA extraction and realtime qPCR assay specific for the $1 \mathrm{~b}$ region of SARS-CoV were conducted as described previously $(3,9)$.

We compared the detection rates of 2 ELISAs and realtime qRT-PCR using the McNemar test and studied the correlation between the optical density values at $450 \mathrm{~nm}$ $\left(\mathrm{OD}_{450}\right)$ of the 2 ELISAs and $\log _{10}$ viral concentrations, as determined by real-time qRT-PCR, by linear regression (SPSS version 11.0, SPSS Inc., Chicago, IL, USA). A p value $<0.05$ was regarded as significant.

A comparison of the 2 ELISAs is shown in the Figure and Table 1 . The cutoffs of the polyclonal antibody-based ELISA have been determined previously, with specificities of $96 \%$ and $99 \%$ for fecal and urine specimens, respectively (11). The baselines of the monoclonal antibody-based ELISA were determined by using 100 control fecal and urine specimens, with mean $\mathrm{OD}_{450}$ values of 0.089 and 0.05 and standard deviation (SD) values of 0.074 and 0.03 , respectively. The specificities of the monoclonal antibody-based ELISA were 93\% for fecal specimens and 98\% for urine specimens, as determined using cutoffs defined as the mean $+2 \mathrm{SD}$. Of 40 fecal samples obtained from SARS patients, 20 (50\%) obtained on days 9 to 23 after onset of symptoms were positive by the polyclonal antibody-based ELISA, and 14 (35\%) obtained on days 2 to 21 were positive by the monoclonal antibody-based ELISA. Of 133 urine samples, 6 (5\%) obtained on days 16 to 32 after onset of symptoms were positive by the polyclonal antibody-based ELISA, and 11 (8\%) obtained on days 6 to 45 were positive by the monoclonal antibody-based ELISA. Results of the polyclonal antibody-based ELISA were comparable with our previous 


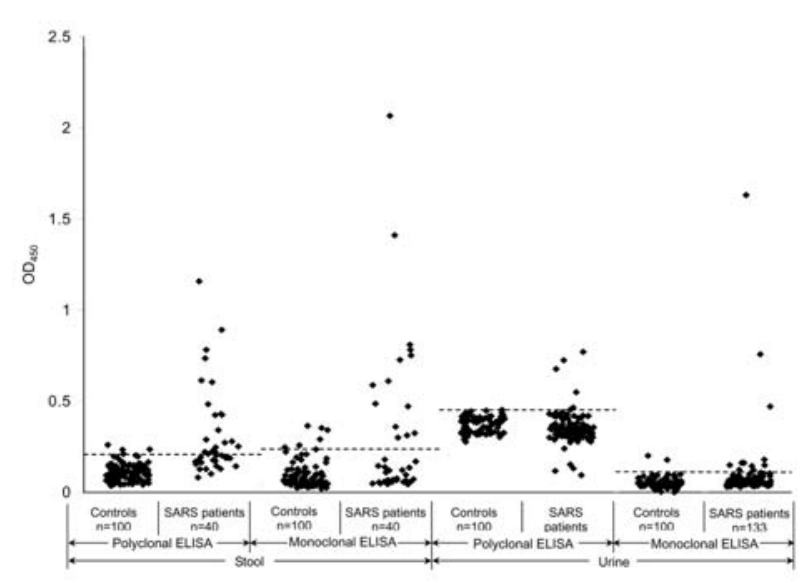

Figure. Evaluation of polyclonal and monoclonal antibody-based enzyme-linked immunosorbent assays (ELISAs) for detecting nucleocapsid protein in fecal and urine specimens. The dashed horizontal lines represent the corresponding cutoff optical density values at $450 \mathrm{~nm}\left(\mathrm{OD}_{450}\right)$. SARS, severe acute respiratory syndrome.

data on different specimens (11). The $\mathrm{OD}_{450}$ values of both fecal (Pearson correlation 0.610, $\mathrm{p}<0.0005$ ) and urine specimens (Pearson correlation 0.475, $\mathrm{p}<0.0005$ ) detected by the 2 ELISAs were significantly correlated.

\section{Conclusions}

The method of choice for early diagnosis of SARSCoV infection should be the qRT-PCR. The sensitivity of qRT-PCR is superior to that of both ELISAs. Moreover, qRT-PCR can detect SARS-CoV earlier in fecal specimens (Tables 1 and 2). Among the 40 fecal samples from SARS patients, 32 (80\%) were positive by qRT-PCR, which was significantly higher than that of the polyclonal (50\%) and monoclonal (35\%) antibody-based ELISAs (McNemar test, $\mathrm{p}<0.005$ and $\mathrm{p}<0.001$, respectively). Of the 133 urine samples from SARS patients, 33 (25\%) were positive by qRT-PCR, which was also significantly higher than that of the polyclonal (5\%) and monoclonal (8\%) antibody-based ELISAs (McNemar test, $\mathrm{p}<0.001$ for both comparisons). When qRT-PCR was used as a standard, the sensitivities of the polyclonal and monoclonal antibody-based ELISAs were $53.1 \%(17 / 32)$ and $43.8 \%(14 / 32)$ in fecal specimens, and $12.1 \%(4 / 33)$ and $15.2 \%(5 / 33)$ in urine specimens, respectively. The qRT-PCR can detect SARS-CoV in fecal specimens obtained on days 1 to 27 after onset of symptoms and in urine specimens obtained on days 9 to 45 . Moreover, 6 (75\%) of the 8 fecal specimens obtained on days 1 to 10 were positive by qRT-PCR. All 3 tests had the highest detection rates in fecal specimens collected on days 16 to 20, which suggested that this was the period of peak viral shedding in stool. The detection rates in urine specimens were much lower than those in fecal specimens in all 3 assays.

SARS-CoV can be detected during the late phase of illness. Since SARS-CoV cannot be readily isolated from SARS patients after week 3 of illness (14), the detection of SARS-CoV beyond this time may be due to prolonged shedding of nonviable viruses in these patients or the presence of neutralizing immunoglobulins in clinical specimens, which has prevented viral replication in cell cultures.

SARS-CoV RNA concentration and ELISA results were correlated. Higher detection rates by both ELISAs

\begin{tabular}{lcccc}
\hline Table 1. Detection of SARS-CoV in clinical specimens by qRT-PCR and ELISA in relation to time from onset of symptoms \\
\hline
\end{tabular}

*SARS-CoV, severe acute respiratory syndrome coronavirus; qRT-PCR, quantitative reverse transcription-polymerase chain reaction; ELISA, enzymelinked immunosorbent assay. 
Table 2. Detection of SARS-CoV by qRT-PCR and ELISA in clinical specimens of patients with SARS*

\begin{tabular}{|c|c|c|c|c|c|c|}
\hline \multirow[b]{2}{*}{$\begin{array}{l}\text { RNA concentration } \\
\text { (copies } / \mathrm{mL} \text { ) }\end{array}$} & \multicolumn{3}{|c|}{ Fecal specimens } & \multicolumn{3}{|c|}{ Urine specimens } \\
\hline & No. specimens & $\begin{array}{c}\text { No. positive by } \\
\text { polyclonal } \\
\text { antibody-based } \\
\text { ELISA }\end{array}$ & $\begin{array}{c}\text { No. positive by } \\
\text { monoclonal } \\
\text { antibody-based } \\
\text { ELISA }\end{array}$ & No. specimens & $\begin{array}{c}\text { No. positive by } \\
\text { polyclonal } \\
\text { antibody-based } \\
\text { ELISA }\end{array}$ & $\begin{array}{c}\text { No. positive by } \\
\text { monoclonal } \\
\text { antibody-based } \\
\text { ELISA } \\
\end{array}$ \\
\hline$<3 \times 10^{2}$ & 8 & 3 & 0 & 100 & 2 & 6 \\
\hline $3 \times 10^{2}-<10^{4}$ & 5 & 3 & 3 & 16 & 1 & 1 \\
\hline $10^{4}-<10^{6}$ & 3 & 0 & 0 & 10 & 1 & 1 \\
\hline $10^{6}-<10^{8}$ & 9 & 5 & 0 & 7 & 2 & 3 \\
\hline $10^{8}-<10^{10}$ & 13 & 8 & 10 & 0 & 0 & 0 \\
\hline$\geq 10^{10}$ & 2 & 1 & 1 & 0 & 0 & 0 \\
\hline Total & 40 & 20 & 14 & 133 & 6 & 11 \\
\hline
\end{tabular}

*SARS-CoV, severe acute respiratory syndrome coronavirus; qRT-PCR, quantitative reverse transcription-polymerase chain reaction; ELISA, enzymelinked immunosorbent assay.

were found in specimens with higher viral concentrations (Table 2). There was also a significant correlation between viral load and ELISA OD $_{450}$ values in fecal specimens tested with the monoclonal antibody-based ELISA (Pearson correlation $0.424, \mathrm{p}=0.003$ ), and in urine specimens tested with both the polyclonal and monoclonal antibody-based ELISAs (Pearson correlation 0.386 and 0.331, respectively, $\mathrm{p}<0.0005$ in both analysis). Although the correlation between viral load and ELISA OD $_{450}$ values in fecal specimens tested with the polyclonal antibody-based ELISA was not significant, there was a trend for such a correlation (Pearson correlation 0.229, $\mathrm{p}=$ 0.078).

In this study, fecal and urine samples were used because they are easier and safer to obtain and more readily available. In our previous reports, nucleocapsid protein was detected by the polyclonal antibody-based ELISA in 83\% of nasopharyngeal aspirates collected on days 11 to 15 after symptom onset and by the monoclonal antibody-based ELISA in $85 \%$ of serum obtained during the first 10 days $(10,11)$. These findings suggest that ELISA may be more useful when used with nasopharyngeal aspirate and serum specimens. However, these specimens were not included in the current study because only small amounts were available. Similar studies should be conducted if such samples are available.

This study was supported by the Research Grant Council Grant (HKU 7532/03M); Vice-Chancellor SARS Research Fund (21395035/39839/20700/420/01 and 21395061/27944/20700/ 420/01), The University of Hong Kong; and Suen Chi Sun Charitable Foundation SARS Research Fund.

Dr. Lau is assistant professor in the Department of Microbiology, University of Hong Kong. Her research interests include emerging infectious diseases and novel pathogens.

\section{References}

1. Ksiazek TG, Erdman D, Goldsmith CS, Zaki SR, Peret T, Emery S, et al. A novel coronavirus associated with severe acute respiratory syndrome. N Engl J Med. 2003;348:1953-66.

2. Peiris JS, Chu CM, Cheng VC, Chan KS, Hung IF, Poon LL, et al. Clinical progression and viral load in a community outbreak of coronavirus-associated SARS pneumonia - a prospective study. Lancet. 2003;361:1767-72.

3. Peiris JS, Yuen KY, Osterhaus AD, Stohr K. The severe acute respiratory syndrome. N Engl J Med. 2003;349:2431-41.

4. Peiris JS, Lai ST, Poon LL, Guan Y, Yam LY, Lim W, et al. Coronavirus as a possible cause of severe acute respiratory syndrome. Lancet. 2003;361:1319-25.

5. Woo PC, Lau SK, Wong BH, Tsoi HW, Fung AM, Chan KH, et al. Detection of specific antibodies to SARS coronavirus nucleocapsid protein for serodiagnosis of SARS coronavirus pneumonia. J Clin Microbiol. 2004;42:2306-9.

6. Woo PC, Lau SK, Wong BH, Chan KH, Chu CM, Tsoi HW, et al. Longitudinal profile of immunoglobulin G (IgG), IgM, and IgA antibodies against SARS coronavirus nucleocapsid protein in patients with pneumonia due to the SARS coronavirus. Clin Lab Diagn Immunol. 2004;11:665-8.

7. Woo PC, Lau SK, Tsoi HW, Chan KH, Wong BHL, Che XY, et al. Relative rates of non-pneumonic SARS coronavirus infection and SARS coronavirus pneumonia. Lancet. 2004;363:841-5.

8. Guan Y, Zheng BJ, He YQ, Liu XL, Zhuang ZX, Cheung CL, et al. Isolation and characterization of viruses related to the SARS coronavirus from animals in southern China. Science. 2003;302:276-8.

9. Poon LL, Wong OK, Chan KH, Luk W, Yuen KY, Peiris JS, et al. Rapid diagnosis of a coronavirus associated with severe acute respiratory syndrome (SARS). Clin Chem. 2003;49:953-5.

10. Che XY, Qiu LW, Pan YX, Wen K, Hao W, Zhang LY, et al. Sensitive and specific monoclonal antibody-based capture enzyme immunoassay for detection of nucleocapsid antigen in sera from patients with severe acute respiratory syndrome. J Clin Microbiol. 2004;42:2629-35.

11. Lau SK, Woo PC, Wong BH, Tsoi HW, Woo GK, Poon RW, et al. Detection of SARS coronavirus nucleocapsid protein in SARS patients by enzyme-linked immunosorbent assay. J Clin Microbiol. 2004;42:2884-9.

12. Borkowsky W, Krasinski K, Pollack H, Hoover W, Kaul A, IlmetMoore T. Early diagnosis of human immunodeficiency virus infection in children less than 6 months of age: comparison of polymerase chain reaction, culture, and plasma antigen capture techniques. J Infect Dis. 1992;166:616-9. 
13. Nubling CM, Unger G, Chudy M, Raia S, Lower J. Sensitivity of HCV core antigen and HCV RNA detection in the early infection phase. Transfusion. 2002;42:1037-45.

All material published in Emerging Infectious Diseases is in the public domain and may be used and reprinted without special permission; proper citation, however, is required.
14. Chan KH, Poon LL, Cheng VC, Guan Y, Hung IF, Kong J, et al. Detection of SARS coronavirus in patients with suspected SARS. Emerg Infect Dis. 2004;10:294-9.

Address for correspondence: Kwok-Yung Yuen, Department of Microbiology, University of Hong Kong, University Pathology Building, Queen Mary Hospital, Hong Kong, People’s Republic of China; fax: 8522855-1241; email: hkumicro@hkucc.hku.hk

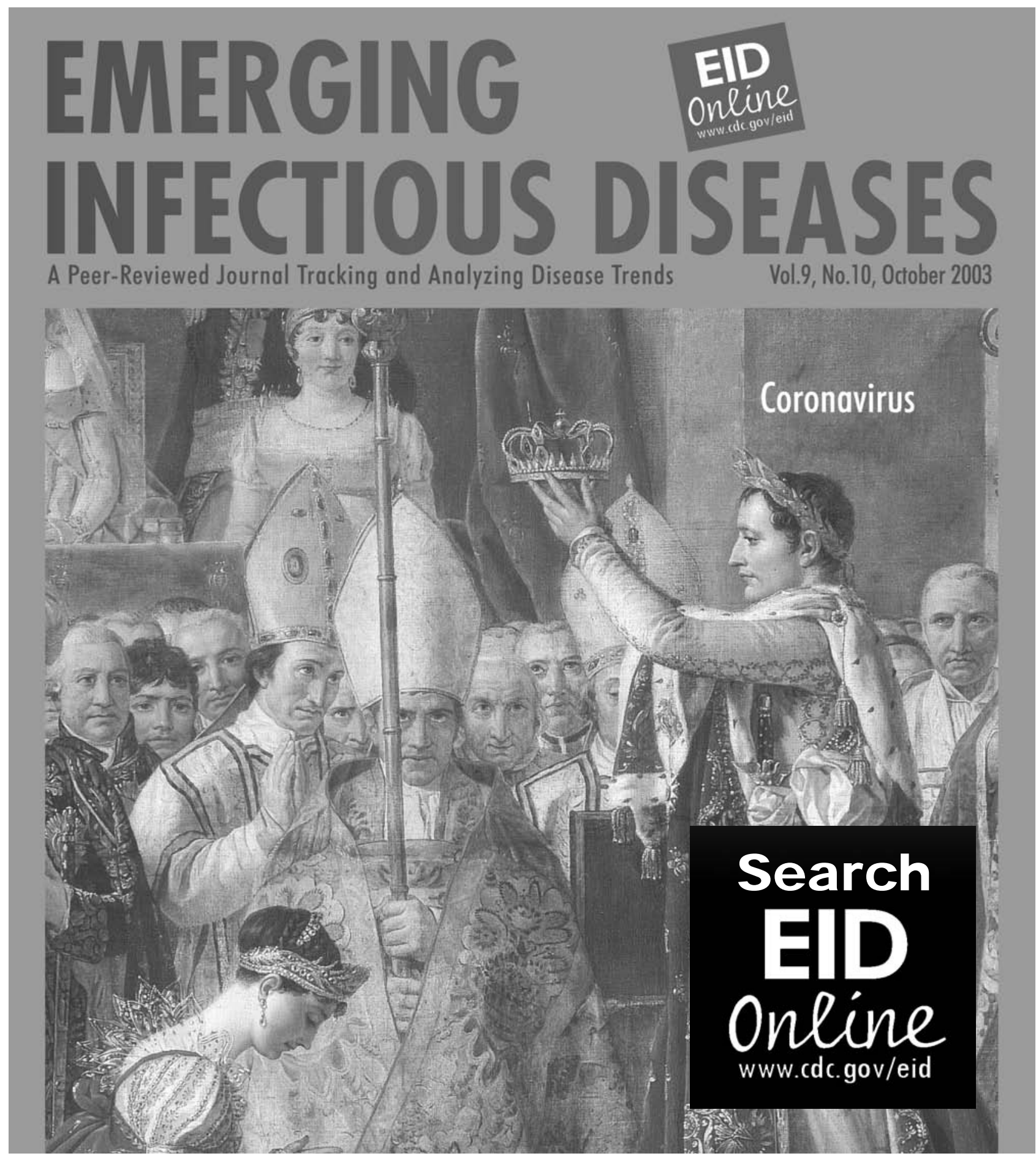

